\title{
Study on association between echocardiographic findings in COPD patients with severity of COPD
}

\author{
MA Kabir ${ }^{1}$, SD Haque ${ }^{2}$, A Baker ${ }^{3}$, MK Alam ${ }^{4}$, SA Rahman ${ }^{5}$
}

\begin{abstract}
Background: Patients with chronic obstructive pulmonary disease (COPD) are at increased risk of developing cardiovascular disease. Echocardiography (ECHO) carries information about cardiac diseases and prognosis in COPD patients. Objective: To find out the Echocardiography changes in COPD patients and to assess Right ventricular (RV) dysfunction by echocardiography and correlate with the disease severity. Methods: A prospective study was conducted on 70 patients admitted with symptoms and signs suggestive of COPD in the Department of Medicine, Gazi Medical College and Hospital (GMCH), Khulna from January 2017 to December 2018. Patients were diagnosed clinically as having COPD with confirmation by spirometry. The patients with asthma, bronchiectasis, tuberculosis, pneumoconiosis, restrictive lung disease like kyphoscoliosis, rheumatic, congenital, ischemic heart disease and hypertension were excluded from the present study. Results: Regarding symptoms, majority 65 (92.9\%) patients had breathlessness, $58(82.9 \%)$ had cough with sputum, 25 (35.7\%) had swelling of feet. Regarding signs, 68 (97.1\%) patients had tachypnea, 24 (34.3\%) had raised JVP, 23 (32.9\%) had loud P2 suggestive of pulmonary arterial hypertension. Regarding echocardiographic findings, $42(60.0 \%)$ patients had Cor pulmonale, 32 (45.7\%) had LVDD, 31 (44.3\%) had RVH, 30 (42.9\%) had PAH, $29(41.4 \%)$ patients had RA/RV dilation, 11 (15.7\%) had RVSD and 9 (12.9\%) had LVH. Table 08 shows RA/RV dilatation, $\mathrm{RVH}$, Cor pulmonale, $\mathrm{PAH}$ and LVDD were statistically significant $(\mathrm{p}<0.05)$ when compared with severity of COPD. Conclusion: High occurrence of cardiac co morbidities such as PAH, RV dysfunction and LV dysfunction accompanied COPD patients. The severity of complications increased with severity of COPD which makes a linear relation. The 2D-echocardiography is more sensitive than radiography and clinical methods in detecting cardiovascular complications like $\mathrm{PAH}$, 'p' pulmonale and RV dysfunction in COPD patients.
\end{abstract}

Key words: COPD, 2D-ECHO.

1. Dr. Muhammad Ashraful Kabir, Assistant Professor, Department of Medicine, Gazi Medical College, Khulna

2. Dr. Syed Didarul Haque, Assistant Professor, Department of Pharmacology, Gazi Medical College, Khulna

3. Prof. Dr. Abu Baker, Professor and Head (Ex), Department of Medicine, Gazi Medical College, Khulna

4. Dr.Mohammed Khorshed Alam, Consultant (Gastro-enterology), Gazi Medical College Hospital, Khulna

5. Dr. Sk. Anisur Rahman, Consultant (Cardiology), Gazi Medical College Hospital, Khulna 
Introduction

Chronic obstructive pulmonary disease is the fourth leading cause of mortality worldwide. It is defined as a disease categorized by airflow limitation that is not fully reversible. Patients with chronic obstructive pulmonary disease (COPD) are at increased risk of cardiovascular disease. Electrocardiography (ECG) and Echocardiography carries information about cardiac disease and prognosis in COPD patients. ${ }^{1}$

Cardiovascular disease accounts for significant morbidity and mortality in chronic obstructive pulmonary disease (COPD). Its prevalence and mechanisms of association have not been elucidated. ${ }^{2}$ Chronic obstructive pulmonary disease (COPD) includes emphysema, an anatomically defined condition characterized by destruction and enlargement of the lung alveoli; chronic bronchitis, a clinically defined condition with chronic cough and phlegm; and small airway disease, a condition in which small bronchioles are narrowed. ${ }^{3}$ COPD is a powerful and independent risk factor for cardiovascular morbidity and mortality which includes right ventricular (RV) dysfunction and cor pulmonale secondary to pulmonary arterial hypertension (PAH), left ventricular dysfunction. Echocardiography provides a rapid, noninvasive, portable, and accurate method to evaluate cardiac functions. ${ }^{4}$

\section{Materials and methods}

A prospective study is conducted on 70 patients admitted with symptoms and signs suggestive of COPD in Gazi Medical College and Hospital $(\mathrm{GMCH})$, Khulna from January 2017 to December 2018. Patients were diagnosed clinically as having COPD with confirmation by spirometry. The patients with asthma, bronchiectasis, tuberculosis, pneumoconiosis, restrictive lung disease like kyphoscoliosis, rheumatic, congenital, ischemic heart disease and hypertension were excluded from the study. All enrolled patients were informed about nature of the study and their rights to refuse. The informed written consent was taken from patients before including in the study. All the 70 randomly selected COPD patients were studied clinically, radiologically, electrocardiographically, echocardiogaphically and also with pulmonary function tests. Patients were investigated when their disorder stabilized. Patients were asked about the duration of symptoms like breathlessness, cough, nature and diurnal variation of expectoration and severity of breathlessness to clinically categorize them into predominant chronic bronchitis and predominant emphysema. Patients were also inquired about history of pedal edema, puffiness of face, right hypochondriac pain, and distension of abdomen, to know whether the patient had developed RV dysfunction.

A detailed clinical examination was carried out in the proforma. Pulmonary function tests were done in all patients and they were graded according to the severity of COPD with guidelines given by Global initiative for Obstructive Lung Disease (GOLD). Chest $\mathrm{x}$-ray, twelve lead electrocardiogram, and 2-D Echo were done to evaluate the severity of RV dysfunction. Various observations in the study were analyzed and the severity of COPD was correlated with the echocardiographic features of right ventricular dysfunction. The statistical software SPSS 23.0 was used for the analysis of data. Microsoft word and Excel were used to generate graphs, tables etc.

\section{Results}

Table 01 shows majority 29 (41.4\%) patients belonged to age 51-60 years with mean age was $53.7 \pm 9.5$ years. Table 02 shows distribution of study patients according to gender: 57 $(81.4 \%)$ were males and $13(18.6 \%)$ were females. Male to female ratio was $4.4: 1$. Table 03 shows majority 19 (33.3\%) patients had duration of smoking 20-29 in pack years with 
mean duration of smoking in pack $32.5 \pm 8.4$ years. Table 04 shows that regarding symptoms, majority $65(92.9 \%)$ patients had breathlessness, 58 (82.9\%) had cough with sputum, $25(35.7 \%)$ had swelling of feet. Regarding signs, 68 (97.1\%) patients had tachypnea, 24 (34.3\%) had raised JVP, 23 (32.9\%) had loud P2 suggestive of pulmonary arterial hypertension. Table 05 shows mild COPD was found in $3(4.3 \%)$, moderate 17 $(24.3 \%)$, severe $31(44.3 \%)$ and very severe $19(27.1 \%)$. Table 06 shows more than two third $48(68.6 \%)$ patients had emphysema, 31 $(44.3 \%)$ had increased bronchovascular marking, 20 (28.6\%) had prominent RDA >16 $\mathrm{mm}$ and $13(18.6 \%)$ had cardiomegaly. Table 07 shows regarding echocardiographic findings $42(60.0 \%)$ patients had Cor pulmonale, 32 (45.7\%) had LVDD, 31 (44.3\%) had $\mathrm{RVH}, 30$ (42.9\%) had PAH, 29 (41.4\%) patients had RA/RV dilation, $11(15.7 \%)$ had RVSD and 9 (12.9\%) had LVH. Table 08 shows RA/RV dilatation, RVH, Cor pulmonale, PAH and LVDD were statistically significant $(p<0.05)$ when compared with severity of COPD.

Table 01: Distribution of the study patients by age $(n=70)$

\begin{tabular}{|l|c|c|}
\hline Age (years) & Frequency & Percentage \\
\hline$\square 40$ & 8 & 11.4 \\
\hline $41-50$ & 23 & 32.9 \\
\hline $51-60$ & 29 & 41.4 \\
\hline $61-70$ & 9 & 12.9 \\
\hline$>70$ & 1 & 1.4 \\
\hline Mean $\pm S D$ & \multicolumn{2}{|c|}{$53.7 \pm 9.5$} \\
\hline
\end{tabular}

Table 02: Distribution of the study patients by gender $(n=70)$

\begin{tabular}{|l|c|c|}
\hline \multicolumn{1}{|c|}{ Sex } & Frequency & Percentage \\
\hline Male & 57 & 81.4 \\
\hline Female & 13 & 18.6 \\
\hline
\end{tabular}

Table 03: Distribution of the study patients by duration of tobacco use $\left(n=57^{*}\right)$

\begin{tabular}{|l|c|c|}
\hline $\begin{array}{c}\text { Duration of } \\
\text { smoking (in } \\
\text { pack years) }\end{array}$ & Frequency & Percentage \\
\hline$<10$ & 5 & 8.8 \\
\hline $10-19$ & 15 & 26.3 \\
\hline $20-29$ & 19 & 33.3 \\
\hline $30-39$ & 11 & 19.3 \\
\hline$>40$ & 7 & 12.3 \\
\hline Mean \pm SD & \multicolumn{2}{|c|}{$32.5 \pm 8.4$} \\
\hline
\end{tabular}

*only male patients used tobacco.

Table 04: Distribution of the study patients by sign and symptoms $(n=70)$

\begin{tabular}{|l|c|c|}
\hline \multicolumn{1}{|c|}{$\begin{array}{c}\text { Sign and } \\
\text { symptoms }\end{array}$} & Frequency & Percentage \\
\hline Symptoms & & 92.9 \\
\hline Breathlessness & 65 & 82.9 \\
\hline $\begin{array}{l}\text { Cough with } \\
\text { sputum }\end{array}$ & 58 & 35.7 \\
\hline Swelling of feet & 25 & 17.1 \\
\hline Fever & 12 & 2.9 \\
\hline $\begin{array}{l}\text { Decreased } \\
\text { urine output }\end{array}$ & 2 & 97.1 \\
\hline Signs & 68 & 34.3 \\
\hline Tachypnea & 24 & 32.9 \\
\hline Raised JVP & 23 & 24.3 \\
\hline $\begin{array}{l}\text { Loud P2 } \\
\text { suggestive of } \\
\text { pulmonary } \\
\text { arterial } \\
\text { hypertension }\end{array}$ & 17 & 30.0 \\
\hline Pedal edema & 21 & 27.1 \\
\hline $\begin{array}{l}\text { Parasternal } \\
\text { heave }\end{array}$ & 19 & 24 \\
\hline Cyanosis & 17 & \\
\hline Ascites & 6 & \\
\hline
\end{tabular}


Table 05: Distribution of the study patients by severity of COPD $(n=70)$

\begin{tabular}{|l|c|c|c|}
\hline $\begin{array}{c}\text { Severity of } \\
\text { COPD }\end{array}$ & $\begin{array}{c}\text { FEV 1\% } \\
\text { predict } \\
\text { ed }\end{array}$ & Frequency & Percentage \\
\hline Mild & $>80$ & 3 & 4.3 \\
\hline Moderate & $50-79$ & 17 & 24.3 \\
\hline Severe & $30-49$ & 31 & 44.3 \\
\hline Very severe & $<30$ & 19 & 27.1 \\
\hline
\end{tabular}

Table 06: Distribution of the study patients by radiological findings $(n=70)$

\begin{tabular}{|l|c|c|}
\hline $\begin{array}{l}\text { Radiological } \\
\text { findings }\end{array}$ & Frequency & Percentage \\
\hline Emphysema & 48 & 68.6 \\
\hline $\begin{array}{l}\text { Increased } \\
\text { bronchovascular } \\
\text { Marking }\end{array}$ & 31 & 44.3 \\
\hline $\begin{array}{l}\text { Prominent } \\
\text { RDPA }>16 \mathrm{~mm}\end{array}$ & 20 & 28.6 \\
\hline Cardiomegaly & 13 & 18.6 \\
\hline
\end{tabular}

Table 07: Distribution of the study patients by echocardiographic findings $(n=70)$

\begin{tabular}{|l|c|c|}
\hline $\begin{array}{c}\text { Echocardiographic } \\
\text { findings }\end{array}$ & Frequency & Percentage \\
\hline Cor pulmonale & 42 & 60.0 \\
\hline LVDD & 32 & 45.7 \\
\hline RVH & 31 & 44.3 \\
\hline PAH & 30 & 42.9 \\
\hline RA/RV dilatation & 29 & 41.4 \\
\hline RVSD & 11 & 15.7 \\
\hline LVH & 9 & 12.9 \\
\hline
\end{tabular}

Table 08: Association between echocardiographic findings with severity of COPD

\begin{tabular}{|l|c|c|c|c|c|c|}
\hline $\begin{array}{c}\text { Echocardiographic } \\
\text { findings }\end{array}$ & Total & $\begin{array}{c}\text { Mild } \\
(\mathbf{n = 3})\end{array}$ & $\begin{array}{c}\text { Moderate } \\
\mathbf{n = 1 7}(\mathbf{\%})\end{array}$ & $\begin{array}{c}\text { Severe } \\
\mathbf{n = 3 1}(\mathbf{\%})\end{array}$ & $\begin{array}{c}\text { Very } \\
\text { severe } \\
\mathbf{n = 1 9}(\%)\end{array}$ & p value \\
\hline Cor pulmonale & 42 & 0 & $4(23.5)$ & $21(67.7)$ & $17(89.5)$ & $0.001^{\mathrm{s}}$ \\
\hline LVDD & 32 & 0 & $5(29.4)$ & $13(41.9)$ & $14(73.7)$ & $0.014^{\mathrm{s}}$ \\
\hline RVH & 31 & 0 & $3(7.6)$ & $13(41.9)$ & $15(78.9)$ & $0.001^{\mathrm{s}}$ \\
\hline PAH & 30 & 0 & $6(35.3)$ & $11(35.5)$ & $13(68.4)$ & $0.027^{\mathrm{s}}$ \\
\hline RA/RV dilatation & 29 & $\mathbf{0}$ & $4(23.5)$ & $12(38.7)$ & $13(68.4)$ & $0.012^{\mathrm{s}}$ \\
\hline RVSD & 11 & 0 & $1(5.9)$ & $4(12.9)$ & $6(31.6)$ & $0.130^{\text {ns }}$ \\
\hline LVH & 9 & 0 & $1(5.9)$ & $3(9.7)$ & $5(26.3)$ & $0.209^{\text {ns }}$ \\
\hline
\end{tabular}

$\mathrm{s}=$ significant; $\mathrm{ns}=$ not significant

$p$ value reached from Chi square test

\section{Discussion}

In this study it was observed that, the majority $29(41.4 \%)$ patients belonged to age 51-60 years with mean age $53.7 \pm 9.5$ years. Khatri et al.5 reported the mean age was $69.85 \pm$ 10.36 years with youngest being 40 and oldest being 95 years. Jatav et al. 4 observed that the maximum numbers of COPD patients $(70 \%)$ in their study were in the 6 th and 7 th decades, mean age of presentation was 63.18 years. Chaudhari and Shrimali1 showed that the maximum numbers of COPD patients $(70 \%)$ in their study were in the 6 th and 7 th decades, mean age of presentation was $52.54 \pm 9.55$ years. In our study, it was observed that $57(81.4 \%)$ were males and $13(18.6 \%)$ were females. Male to female ratio was $4.4: 1$. Similar observation was found in different studies. Jatav et al.4 found male to female ratio of $6.14: 1$ in their study. Number of males in the study by Krishnan et al.6 and Vikhe et al.7 were $84 \%$ and $88 \%$ respectively, which is similar to present study (86\%). Chaudhari and Shrimali1 reported thatn82 were male and 18 were female, with male to 
female ratio $4.55: 1$. Khatri et al. 5 found there were $40(47 \%)$ males and $46(53 \%)$ females in their study population.

In this study it was observed that the majority $19(33.3 \%)$ patients had duration of smoking 20-29 in pack years with mean duration of smoking in pack $32.5 \pm 8.4$ years. In the study of Jatav et al.4, majority of the patients (86\%) had history of smoking. The mean duration of smoking observed in the study was 25.06 years. Majority of smokers (56\%) had history of smoking more than 20 pack years. In the study by Krishnan et al.6 mean duration of smoking was 22.62 years which is similar to the present study. In the study of Chaudhari and Shrimali1, majority of the patients $(86 \%)$ had history of smoking. Majority of smokers $(80.3 \%)$ had history of smoking more than 10 pack years.

In current study it was observed that regarding symptoms, majority $65(92.9 \%)$ patients had breathlessness, 58 (82.9\%) had cough with sputum, $25(35.7 \%)$ had swelling of feet. Regarding signs, 68 (97.1\%) patients had tachypnea, 24 (34.3\%) had raised JVP, 23 (32.9\%) had loud P2 suggestive of pulmonary arterial hypertension. In comparison with the study of Jatav et al.4 they showed most of the patients had cough with sputum $(80 \%)$ and breathlessness on presentation (96\%). 32\% presented with swelling of feet, $16 \%$ had fever, $4 \%$ had decreased urine output. Most common sign at presentation is tachypnea in $96 \%$ followed by $35 \%$ had loud $\mathrm{P} 2$ suggestive of pulmonary arterial hypertension, $30 \%$ of the patients had parasternal heave, the clinical evidence of right ventricular hypertrophy. Evidence of congestive cardiac failure like raised JVP in 36\%, pedal edema in 32\% and ascites in $9 \%$ cases. $27 \%$ of the patients had cyanosis which is evidence of a hypoxic state. Chaudhari and Shrimali1 reported breathlessness was the commonest symptom found in all $100 \%$ patients followed by cough with expectoration (94\%). while right hypochondrial $(\mathrm{RHC})$ pain was the least common symptom found in $8 \%$ patient. The most common sign was tachypnea present in $70 \%$ patients $(70 \%)$, Barrel Shaped chest in $58 \%$ patients, pedal edema was $36 \%$; while right hypochondrial (RHC) tenderness was present in $4 \%$ patients.

In this study it was showed mild COPD was found in $3(4.3 \%)$, moderate $17(24.3 \%)$, severe $31(44.3 \%)$ and very severe 19 $(27.1 \%)$. Jatav et al.4 observed that majority of patients (44\%) had severe and very severe COPD (31\%), 4\% patients had mild COPD and $22 \%$ had moderate COPD. Comparing with other studies i.e. Sekhar et al.8 the present study had almost similar findings. In Dave et al.9 study maximum number of patients were in very severe category (38\%). Chaudhari and Shrimali1 observed that majority of patients had severe COPD (62\%), 4\% patients had mild COPD and $3(4 \%)$ had moderate COPD. Freixa et al.2 reported mild COPD was found $6.0 \%$, moderate $48.0 \%$, severe $39.0 \%$ and very severe $8.0 \%$.

In current study it was observed that more than two third $48(68.6 \%)$ patients had emphysema, $31(44.3 \%)$ had increased bronchovascular marking, 20 (28.6\%) had prominent RDA > $16 \mathrm{~mm}$ and $13(18.6 \%)$ had cardiomegaly. Jatav et al.4 reported in chest X-ray, $72 \%$ of the patients had features of emphysema. $42 \%$ of the patients had increased brochovascular marking suggestive of chronic bronchitis. X-ray evidence of pulmonary hypertension i.e. prominent right descending pulmonary artery (RDPA) was present in $30 \%$ of the patients. Cardiomegaly on X-ray was present in $20 \%$. Chaudhari and Shrimali1 observed that in chest X-ray, $80 \%$ of the patients had features of emphysema. $68 \%$ of the patients had increased brochovascular marking suggestive of chronic bronchitis. X-ray evidence of pulmonary hypertension i.e. prominent right descending pulmonary artery (RDPA) was present in $30 \%$ of the patients. Cardiomegaly on X-ray was present in $24 \%$. The incidence of chest $X$-ray signs 
correlated with the study of Krishnan et al.10 and Suma et al. ${ }^{11}$

Regarding echocardiographic findings, 42 $(60.0 \%)$ patients had Cor pulmonale, 32 (45.7\%) had LVDD, 31 (44.3\%) had RVH, 30 (42.9\%) had PAH, 29 (41.4\%) patients had RA/RV dilation, 11 (15.7\%) had RVSD and 9 $(12.9 \%)$ had LVH. Jatav et al.4 most common echocardiographic finding was Cor pulmonale, $62 \%$ of the patients in this study had echocardiographic evidence of cor pulmonale. Pulmonary arterial hypertension (PAH) which is defined as pulmonary arterial systolic pressure (PASP) $>30 \mathrm{mmHg}$ was observed in $44 \%$ cases. $43 \%$ had features of RA/RV dilatation, $42 \%$ had $\mathrm{RVH} 46 \%$ had LVDD, $14 \%$ had RVSD and $11 \%$ had LVH. Signs correlated with the study of Sekhar et al.8 and Suma et al. ${ }^{11}$ Most common echocardiographic finding was Cor pulmonale, $62 \%$ of the patients in this study had echocardiographic evidence of cor pulmonale. Other echocardiographic findings were $\mathrm{PAH}$ in $44 \%$ cases, RA/RV dilatation in $43 \%, \mathrm{RVH}$ in $42 \%$, LVDD in $46 \%$, RVSD in $14 \%$ and LVH in $11 \%$ of cases. Similar observations were present in previous studies. ${ }^{6-8}$ Chaudhari and Shrimali1 reported analysis of echocardio graphic findings which showed that most common echocardiographic finding was Pulmonary arterial hypertension $(\mathrm{PAH})$. $\mathrm{PAH}$ which is defined as pulmonary arterial systolic pressure (PASP) $>30 \mathrm{mmHg}$ was observed in $54 \%$ cases. $52 \%$ had features of RV dilatation, $42 \%$ had RA Dilation, $28 \%$ had RA Hypertrophy, $20 \%$ had IVS motion abnormality and 14\% RV Failure had 8\% Normal. Similar incidences were found in some previous studies. ${ }^{10-12}$

In this study it was observed that RA/RV dilatation, $\mathrm{RVH}$, Cor pulmonale, $\mathrm{PAH}$ and LVDD were statistically significant $(p<0.05)$ when compared with severity of COPD. Jatav et al.4 analysed echocardiographic findings with disease severity, which showed that in mild category no case of RA/RV dilatation was present while in moderate, severe and very severe categories it was present in $27.27 \%$, $40.90 \%$ and $63.33 \%$ of cases respectively. $\mathrm{RVH}$ was also not present in mild category while in moderate, severe, and very severe categories it was present in $27.27 \%, 38.63 \%$ and $63.33 \%$ of cases respectively. Cor pulmonale was observed in $0 \%$ cases in mild category patients while in moderate, severe and very severe categories it was present in $27.27 \%, 68.18 \%$ and $86.67 \%$ of cases respectively. $\mathrm{PAH}$ was observed in $0 \%$ cases in mild category patients while in moderate, severe and very severe categories it was observed in $40.90 \%, 36.36 \%$ and $63.33 \%$ of cases respectively. RVSD was observed in $0 \%$ cases in mild category while in moderate, severe and very severe categories it was observed in $4.94 \%, 9.09 \%$ and $30 \%$ of cases respectively. All echocardiographic findings of RV dysfunction i.e. PAH, Cor pulmonale, RA/RV dilatation, RVH and RVSD correlated significantly with disease severity $(p<0.05)$. Chaudhari and Shrimali1 observed that severe category of COPD has abnormal echocardiographic findings: RVD (74.1\%), PAH (67.7\%), RAD (54.8\%). Moderate COPD had PAH (29.4\%), RVD (23.5\%), RVH (17.6\%) and normal Echo findings (17.6\%). The echo signs of right atrium enlargement, right ventricle dilatation and pulmonary hypertension correlated significantly with the severity of COPD $(p<0.05)$.

\section{Conclusion}

High occurrence of cardiac co morbidities such as PAH, RV dysfunction and LV dysfunction accompanied COPD patients. The severity of complications increases with severity of COPD which makes a linear correlation. The 2D-echocardiography is more sensitive than radiography and clinical methods in detecting cardiovascular complications like $\mathrm{PAH}$, ' $p$ ' pulmonale and RV dysfunction in COPD patients. 


\section{Acknowledgements}

The authors are greatful to $\mathrm{GMCH}$ authority for giving permission to conduct this research work. The authors are also thankful to all the patients and their families who participated in the research work and they also pray for the well-being of the patients.

\section{References}

1. Chaudhari R, Shrimali L. Study of clinical, electrocardiographic and echocardiographic profile in patients with chronic obstructive pulmonary disease. Int $\mathrm{J}$ Res Med Sci 2018;6:1716-20.

2. Freixa X, Portillo K, Pare C, GarciaAymerich J, Gomez PF and Benet M et al. Echocardiographic abnormalities in patients with COPD at their first hospital admission, Eur Respir J 2013; 41: 784-791.

3. Reilly J, Silverman. chronic obstructive pulmonary disease. In: Kasper Dennis, Hauser Stephen, Jameson J. Larry, S. Fauci anthony, Longo, Loscalzo. Harrison's principles of internal medicine 19th edition, from New York, NY:McGraw Hill. 2015;2:1700.

4. Jatav VS, Meena SR, Jelia $S$, Jain $P$, Ajmera D, Agarwal V, Dayma CL, Arif M. Echocardiographic findings in chronic obstructive pulmonary disease and correlation of right ventricular dysfunction with disease severity. Int J Adv Med 2017;4:476-80.

5. Khatri D, Karki $P$, Shrestha $D B$, Khatri R, Thapa RK, Panta C, Budhathoki L. Echocardiographic Findings in Chronic Obstructive Pulmonary disease Patients. BJHS 2018;3(1)5 : 342 - 345.
6. Krishnan RD and Srihari B. A study on the severity of right ventricular dysfunction in correlation with the severity of Lung dysfunction in chronic obstructive pulmonary disease patients- COPD. Am J Sci Med Res. 2015;1(1):112-9.

7. Vikhe VB, Shende PS, Patil RS, Tamakuwala KK, Patil AS, Gupta AP. Cardiovascular complications in chronic obstructive pulmonary disease with reference to $2 \mathrm{D}$ echocardiography findings. Natl J Med Res. 2013;3(4):385-8.

8. Sekhar CG, Sammaiah P, Bookya K, Balaji B. Study of cardiovascular complications in chronic obstructive pulmonary disease with reference to ECG and 2D echocardiography findings. Am J Pharm Health Res. 2016;4(1):97-111

9. Dave L, Dwivedi P, Srivastava N, Yadav BS, Dohre R. A study of cardiovascular manifestations of COPD. Int $\mathrm{J}$ Res Health Sci[Internet]. 2014;2(3):812-7.

10. Krishnan DR, Srihari B. A study on the severity of right ventricular dysfunction in correlation with the severity of lung dysfunction in chronic obstructive pulmonary disease patients-COPD. The Ame J Sci. and Med Res. 2015;1(1):112-9.

11. Suma KR, Srinath S. Electrocardiographic and echocardiographic changes in chronic obstructive pulmonary disease (COPD) of different grades of severity. J Evolution Med Dental Sci. 2015;4(30):5093-102.

12. Kutum US, Deb D, Sarma PC, Deb T, Pujar R. A study on chronic obstructive pulmonary disease (COPD) patients with reference to echocardiographic findings. JEMDS. 2015;4(103):16814-21. 